\title{
Antibiofilm Activity of Mangosteen (Garcinia mangostana L.) Flavonoids against Streptococcus mutans Bacteria
}

\author{
Aulia Ramadhani, ${ }^{1}$ Sri Kunarti, ${ }^{2}$ Laksmiari Setyowati ${ }^{2}$ \\ ${ }^{1}$ Student of Dental Medicine \\ ${ }^{2}$ Teaching Staff of Conservation Dental Medicine \\ Faculty of Dental Medicine, Universitas Airlangga, Surabaya - Indonesia
}

\begin{abstract}
Background: Dental caries is one of the most common infectious diseases and often occurs in the community caused by bacteria. Attached bacteria in the tooth surface for a long time will form a biofilm and will lead to demineralization characterized by damage in the structure of the tooth enamel. The bacteria that cause dental caries and can form biofilms is Streptococcus mutans. The bacteria inside biofilms are more resistant to antibacterial agents. Flavonoids in mangosteen pericarp extract can be a cleaner alternative for the anti-biofilm cavity that has properties against Streptococcus mutans. Purpose: To determine the activity of flavonoids in mangosteen pericarp extract at a certain concentration against Streptococcus mutans bacteria. Methods: This study was a laboratory experimental study with a post-test only control group design. Streptococcus mutans were diluted according to the Mc Farland dilution standard 106 in Tryptic Soy Broth (TSB) medium and put in a flexible U-bottom microtiter plate. Then it was incubated for $5 \times 24$ hours and checked using crystal violet simple staining to see the formation of biofilms. Flavonoid extract of mangosteen pericarp performed serial dilution in a concentration of $100 \%, 50 \%, 25 \%, 12.5 \%, 6.25 \%, 3.125 \%, 1.56 \%$, and $0.78 \%$ was added, and the incubation process were conducted for $1 \times 24$ hours. OD (Optical Density) readings were done with a wavelength of 595 nm. Results: There was a significant difference between the test groups and the positive control group. The concentration of $100 \%$ had the anti-biofilm activity and showed the value of the highest percentage of inhibition, whilst the concentration of $0.78 \%$ showed a minimum biofilm inhibition concentration. The results were demonstrated by a statistical analysis test. Conclusion: Flavonoid extract of mangosteen pericarp at a certain concentration has anti-biofilm activity against Streptococcus mutans biofilm.
\end{abstract}

Keywords: Streptococcus mutans; antibiofilm; flavonoid; mangosteen extract

Correspondence: Aulia Ramadhani ${ }^{1}$, Sri Kunarti ${ }^{2}$, Laskmiari Setyowati ${ }^{3}$, Department of Dental Conservation Dental Medicine, Faculty of Dental Medicine, Universitas Airlangga. Jalan Mayjen Prof Moestopo no. 48, Surabaya, Indonesia. E-mail: rararmdhni@gmail. com¹, attybp@yahoo.co.id², laksmi_dentist@yahoo.com ${ }^{3}$

\section{INTRODUCTION}

Mangosteen (Garcinia mangostana L.) is a plant originating from the Southeast Asian region including Indonesia, Malaysia, Thailand, and Myanmar. Mangosteen which is usually been wasted after the flesh is consumed has a myriad of important health benefits. Mangosteen pericarp is rich in antioxidants such as xanthones and anthocyanins ${ }^{1,2}$. The chemical content of roots, bark, and the pericarp is saponins. Besides, the stem contains flavonoids and polyphenols. The pericarp contains flavonoids, steroids/ terpenoids and quinones, and the elements of sodium, potassium, magnesium, calcium, iron, zinc, and copper. Several studies have mentioned that the active substance in mangosteen pericarp can act as an anti-bacterial and antibiofilm. One of which is the active substance flavonoids.
Flavonoid compounds are polyphenol compounds that have 15 carbon atoms, consisting of two benzene rings connected by a linear chain consisting of three carbon atoms ${ }^{3}$.

Caries is one of the most common infectious diseases and often occurs in the community. Dental caries is a major problem for dental medicine and found in both children and adults. Dental caries is not a new infectious disease in Indonesia. Even, the prevalence of caries in Indonesia is quite high. Meanwhile, according to the 2007 Basic Health Study Report, it was found that cavities or dental caries attacked or suffered by approximately 72.1 percent of Indonesia's population. Bacteria play an important role in the process of dental caries. Various species of bacteria colonize in the oral cavity, especially in dental plaque and these bacteria can produce acids so that the process of demineralization of hard tooth tissue occurs. To survive, 
the oral microorganisms must be attached to the surface and then form biofilms ${ }^{4}$. Streptococcus mutans is one of the bacteria in the process of caries. Streptococcus mutans also have special properties that play a role in caries pathogenesis. Moreover, it also able to produce extracellular polysaccharides (dextran) which facilitates its attachment to the tooth surface with the help of adhesin and glucan polymers that are not soluble in water. One of the virulence factors of Streptococcus mutans is its ability to stick to the tooth surface and form biofilms ${ }^{5}$.

In previous studies, it was found that mangosteen pericarp extract was able to show anti-biofilm properties against Staphylococcus aureus bacteria ${ }^{6}$. From various studies that have existed, the authors did not find study on the effectiveness (power) of the flavonoids active substance against Streptococcus mutans bacterial biofilms. The purpose of this study was to determine the ability of mangosteen pericarp flavonoids at certain concentrations in suppressing the growth of Streptococcus mutans bacterial biofilms.

\section{MATERIALS AND METHODS}

This study was experimental laboratory study with a posttest only control group design using Streptococcus mutans bacteria obtained from the Laboratory of Microbiology, Faculty of Dental Medicine, Universitas Airlangga. There were 8 treatment groups with different concentrations $(100 \%, 50 \%, 25 \%, 12.5 \%, 6.125 \%, 3.125 \%, 1.56 \%$, and $0.78 \%$ ) as well as the positive and negative control groups. Streptococcus mutans bacteria were diluted according to Mc Farland 106 standard in Tryptic Soy Broth (TSB) media and inserted into a U-bottom flexible microtiter plate. Then, it was incubated for $5 \times 24$ and checked using crystal violet simple staining to see the formation of biofilms. Mangosteen pericarp extract flavonoids were firstly diluted into a concentration of $100 \%, 50 \%, 25 \%, 12.5 \%, 6.25 \%, 3.125 \%$, $1.56 \%$, and $0.78 \%$, and then were added and incubated for
$1 \times 24$ hours. Then the reading of the OD value (Optical Density) was performed with a wavelength of $567 \mathrm{~nm}$, and the percentage of inhibition was also calculated.

\section{RESULTS}

The results showed the formation of biofilms by the bacterium Streptococcus mutans which were formed by using an inverted microscope on the 5th day of incubation. Then it was given the material test and incubated again for $1 \times 24$ hours. After that, the reading was done using a microplate reader with a wavelength of $595 \mathrm{~nm}$ and resulted in the form of Optical Density (OD) values and averaged in Table 1. From the mean of OD score, it was reprocessed into the percentage of inhibition and calculated using formula ${ }^{8}$.

\section{(Mean OD Control - Mean OD Concentration) x 100\% Mean OD Control}

Therefore, the inhibition percentage value was obtained as written in Table 2. Statistical data analysis was also performed using ANOVA because the existing data was homogeneous $(\mathrm{p}>0.05)$. ANOVA results showed a significant difference between the whole group $(p<0.05)$. Then a comparative test among concentrations was conducted using statistical analysis test of Post-Hoc Multiple Comparison Test and showed a significant difference between concentrations of $0.78 \%, 1.56 \%, 3.125 \%, 6.25 \%$, $12.5 \%, 25 \%, 50 \%$, and $100 \%$ of the positive control group ( $\mathrm{p}<0.05)$. Meaning that all eight concentrations had antibiofilm activity against Streptococcus mutans.

\section{DISCUSSION}

In this study, mangosteen pericarp extract flavonoids were used with various concentrations, consisting of $100 \%, 50 \%$,

Table 1. The average results of the Optical Density biofilm values of Streptococcus mutans

\begin{tabular}{lccccccccccccc}
\hline & \multicolumn{7}{c}{ Concentration (\%) } \\
\cline { 2 - 9 } & 0.78 & 1.56 & 3.125 & 6.25 & 12.5 & 25 & 50 & 100 \\
\hline Mean & 0.408 & 0.358 & 0.419 & 0.343 & 0.341 & 0.333 & 0.317 & 0.127 & 0.796 & 0.118 & 0.138 & 0.058 & 0.266 \\
\hline
\end{tabular}

Table 2. The result of the calculation of biofilm prohibition percentage

\begin{tabular}{lc}
\hline Group & Inhibition Percentage \\
\hline Mangosteen Pericarp Extract Flavonoid 100\% & $83.9488 \%$ \\
Mangosteen Pericarp Extract Flavonoid 50\% & $60.1859 \%$ \\
Mangosteen Pericarp Extract Flavonoid 25\% & $58.1261 \%$ \\
Mangosteen Pericarp Extract Flavonoid 12.5\% & $57.1213 \%$ \\
Mangosteen Pericarp Extract Flavonoid 6.25\% & $56.8199 \%$ \\
Mangosteen Pericarp Extract Flavonoid 3.125\% & $47.2997 \%$ \\
Mangosteen Pericarp Extract Flavonoid 1.56\% & $54.9611 \%$ \\
Mangosteen Pericarp Extract Flavonoid 0.78\% & $48.7566 \%$ \\
\hline
\end{tabular}


$25 \%, 12.5 \%, 6.25 \%, 3.125 \%, 1.56 \%$, and $0.78 \%$ to see the anti-biofilm ability of mangosteen flavonoids. Replication at each concentration was conducted eight times. And the results obtained were in the form of OD values (Optical Density). After that, the percentage calculation of inhibition was conducted using a formula. At concentrations of $0.78 \%$ and $1.56 \%$, there was an increase in the percentage of inhibition. However, at a concentration of $3.125 \%$, the percentage of inhibition decreased. The escalation of the inhibition was seen again in the concentration of $6.25 \%$ up to the concentration of $100 \%$.

At a concentration of $0.78 \%$ with an inhibition percentage of $48.7566 \%$, it could be said to be the Minimum Biofilm Inhibition Concentration value through statistical analysis tests following the opinion of Chamdit and Siripermpool (2012) ${ }^{7}$ stating that the Minimum Biofilm Inhibition Concentration was the lowest concentration of an anti-biofilm material to inhibit the formation of biofilms. However, to find out more exact MBIC contained in mangosteen pericarp flavonoids, further study needs to be done using a concentration range above or below the concentration of $0.78 \%$. The results of the study proven by One way ANOVA analysis test showing a significant difference $(\mathrm{p}<0.05)$ and the Post-Hoc Multiple Comparison test showing the concentrations of $0.78 \%, 1.56 \%, 3.125 \%$, $6.25 \%, 12,5 \%, 25 \%, 50 \%$, and $100 \%$ indicated significant differences with the control group. Also, the concentration that had the highest inhibitory ability of this study was at a concentration of $100 \%$ with a percentage of inhibition of $83.9488 \%$.

The results of the study showed that there were significant differences compared to the existing theories. Mangosteen pericarp flavonoids were proven to have anti-biofilm. Based on the theory, flavonoids can damage the bacterial cell membrane through the destruction of the lipid layer on the bacterial membrane and cause the barrier cell membrane function to be disrupted. Flavonoid activity results in damage in the bacterial cell membrane so that there will be a decrease in the function of the bacterial membrane barrier which leads to intramembrane leakage. This causes bacterial aggregation to decrease, so the bacterial colonies that form on the surface will also decrease ${ }^{9}$. Flavonoids also disrupt the cell signaling activity by reducing $\alpha$-hemolysin, a bacterial exotoxin, and results in permanent adhesion and inhibition of colony formation, on the tooth surface.

Regarding the inhibition of biofilms, the ability of flavonoid compounds in the phenol group to inactivate bacterial enzymes stimulates the activity of the glucosyltransferase enzyme used by bacteria to synthesize sucrose in the media into glucans (EPS). As a result, the formation of biofilms is inhibited because the amount of glucan as a medium for attachment of bacteria is small or limited. This can indicate that the flavonoid compounds in phenols can inhibit the formation of biofilms in bacteria ${ }^{11}$.

From the results of the study, it can be concluded that mangosteen skin flavonoids have the ability as anti-biofilms against Streptococcus mutans bacteria, and the concentration of $100 \%$ flavonoids has the highest anti-biofilms ability.

\section{REFERENCES}

1. Kristenses, L. 2005. Mangosteen Ebook. Secrets of the Natural Health Benefits of Xanthones from Mangosteen Fruit. Available from: http://www.Laurie-Info.here.ws Accessed on Sunday, November 242013 at 20:06 PM

2. Weecharangsan W, Opanasopit P, Sukma M, Ngawhirunpat T, Sotanaphun U, dan Siripong P. 2006. Antioxidative and neuroprotective activities of extract from the fruit hull of mangosteen (Garcinia mangostana Linn.) Med Princ Pract. 15(4): 281-287.

3. Hartanto SB. 2011. Mengobati Kanker Dengan Manggis. Yogyakarta: Penerbit Second Hope. P.24.

4. Fejerskov O, Edwina K. 2008. Dental Caries: The Disease and its Clinical Management Second Edition. Blackwell Publishing: UK. P.166

5. Pandit S, Kim HJ, Kim JE, Jeon JG. 2011. Separation of an Effective Fraction from Turmeric against Streptococcus mutans Biofilms by the Comparison of Curcuminoid Content and Anti-acidogenic Activity. Food Chemistry 126 (4): $1565-70$

6. Dyan Putri R, Nony Puspawati. 2012. Uji Aktvitas Antibakteri Ekstrak Kulit Manggis Terhadap Staphylococcus Aureus. Analis Kesehatan Fakultas Ilmu Kesehatan Universitas Setiabudi.

7. Chamdit S, Siripermpool P. 2012. Antimicrobial Effect of Clove and Lemongrass Oils Against Planktonic Cells and Biofilm of Staphylococcus aureus. Mahidol University Juournal of Pharmaceuticl Sciences, 39 (2), 28-36.

8. Peeters E, Nelis HJ, Coenye T. 2008. Comparison of multiple methods for quantification of microbial biofilms grown in microtiter plates. Journal of Microbiological Methods 72: 157-165.

9. Cushnie TPT, Lamb AJ. 2005. Detection of galangininduced cytoplasmic membrane damage in Staphylococcus aureus by measuring potassium loss. J Ethnopharmacol 2005; 101:243-8.

10. Cheung AL and G. Zhang. 2002. Global regulation of virulence determinants in Staphylococcus aureus by the SarA protein family. Frontiers in Bioscience, vol. 7, pp. d1825d1842.

11. Ardiana D, Martha PW, Teuku NS, Puji A. 2013. Mouthwash Formulation of Basil Oil (Ocimum basilicum L.) And in Vitro Antibacterial and Antibiofilm Activities Against Streptococcus mutans. Traditional Medicine Journal, 18(2), 2013. 